\title{
History and future of hepatitis B virus control in South Korea
}

\section{Do Young Kim}

Department of Internal Medicine, Yonsei University College of Medicine, Seoul, Korea
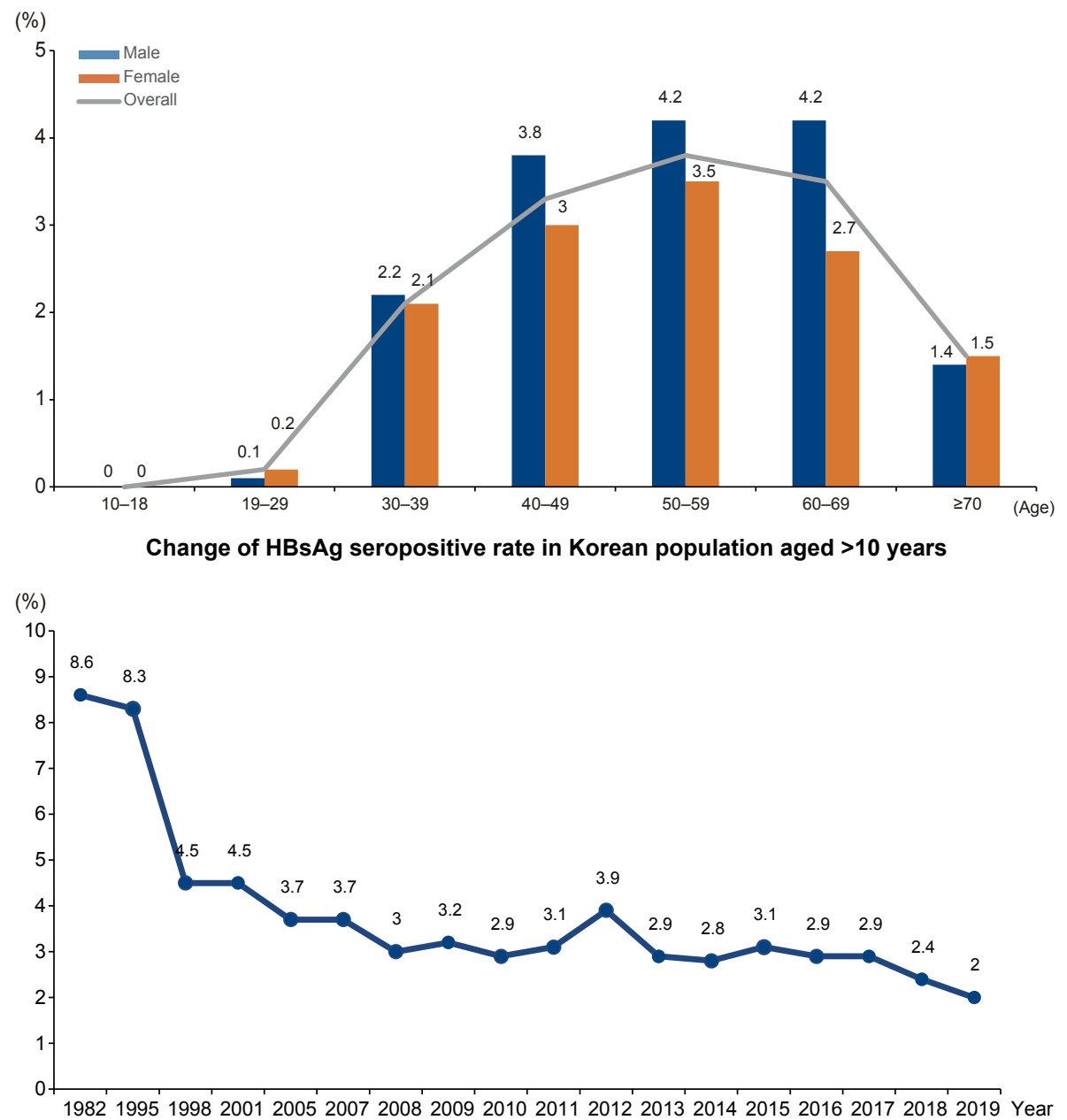

HBsAg seropositive rate in Korean population based on sex, age in 2019

\section{Abbreviations:}

HBsAg, hepatitis B surface antigen; HBV, hepatitis B virus; $H C C$, hepatocellular carcinoma; KASL, Korean Association for the Study of the Liver

\section{Corresponding author : Do Young Kim}

Department of Internal Medicine, Yonsei University College of Medicine, 50-1 Yonsei-ro, Seodaemun-gu, Seoul 03722, Korea

Tel: +82-2-2228-1992, Fax: +82-2-393-6884

E-mail:dyk1025@yuhs.ac

https://orcid.org/0000-0002-8327-3439 
Hepatitis B virus (HBV) is the main etiology of chronic liver diseases in South Korea, accounting for $60-70 \%$ of patients with chronic hepatitis, cirrhosis, and hepatocellular carcinoma (HCC).' Due to high frequencies of vertical transmission, hepatitis B surface antigen (HBsAg) positivity rate was reported to be as high as $7-8 \%$ in the general population and $14.2 \%$ in the school-age children until the 1970s and early 1980s in South Korea. Accordingly, a definitive measure to halt the spread this infection was vaccination. Eventually, in 1983, HBV vaccine was developed in South Korea. This HBV vaccine was effective and also much cheaper than the previously developed vaccines from other countries. To escape the stigma of being a "hepatitis B kingdom" ahead of the Seoul Olympics in 1988, the South Korean government implemented the so-called "Hepatitis B eradication 5-year plan" in 1984, which accelerated a government-initiated preventive project for hepatitis $B$ that became the cornerstone of the national vaccination program for infants and children in 1995. Since 2002, the "Hepatitis B perinatal infection prevention program," which aimed to protect newborns from perinatal infection, supported the cost of immunoglobulin prophylaxis, vaccination, and antigen/antibody testing in babies born from mothers infected with HBV. ${ }^{2}$ The Korea Center for Disease Control and Prevention successfully established this program in over 3,000 institutions nationwide with the cooperation of related academic societies and associations, including the Korean Association for the Study of the Liver (KASL).

The impact of HBV vaccination was evident. Since the national vaccination program began in 1995, HBsAg positive rate decreased significantly from $8.3 \%$ of the total population in 1995 to $4.6 \%$ in $1998,3.7 \%$ in 2005 , and $3.0 \%$ in 2011 . In particular, as more than $95 \%$ of infants were vaccinated nationwide, the current HBsAg-positive rate in adolescents has decreased significantly to less than $0.2 \%$. As a result of such effort and outcomes, in 2008, the World Health Organization certified South Korea with the achievement of regional goal of hepatitis B control. ${ }^{3}$

In addition to HBV vaccination, active and proper use of antiviral drugs, including interferon and nucleos(t)ide analogues, is also an important contributing factor to significantly decrease morbidity and mortality from HBV infection. ${ }^{4}$ The KASL has been working to remove barriers to access to antiviral therapy, particularly in terms of lowering the limitation of treatment indication determined by the national health insurance system.

However, about $3 \%$ of the Korean population is still infected with HBV. While the HBsAg-positive rate ranges between $0-0.2 \%$ in people aged 30 years or younger due to the national vaccination program, the rate is still high among those in their 40s, 50s, and 60 s $(3.4 \%, 3.9 \%, 3.5 \%$, respectively). Moreover, the prevalence of HBV in males in these age groups is over $4 \%$. As the "Hepatitis B perinatal infection prevention program" began in 2002, the cohort effect of highly prevalent HBV infection in the population born before 1992 is expected to continue for at least 30 years. The problem is that the socioeconomically active population is suffering from HBV-related chronic hepatitis, cirrhosis, and HCC. In a study using claims data from the national health insurance service, the total socioeconomic costs increased from 127.1 million USD in 2002 to 459.1 million USD in 2015, mainly due to the increase in pharmaceutical costs, which accounted for the largest proportion of total costs since 2009. Furthermore, the healthcare costs for HBV infection accounted for $0.13 \%$ of the national health expenditure in 2002, and later increased to $0.31 \%$ in $2015 .{ }^{5}$

Babies born from mothers with high HBV concentration are still at risk of being infected with $\mathrm{HBV}$, even if they are perinatally vaccinated. Therefore, it is mandatory and recommended to treat pregnant women with antiviral agent in intrauterine pregnancy at 24-32 weeks. ${ }^{6}$ Such an effort will help South Korea become a HBV-free country in the future. For adult patients who are already infected with HBV, it would be crucial to increase the disease awareness of $\mathrm{HBV}$, in addition to regularly checking their liver condition to prevent disease progression and detect early HCC.?

\section{Conflicts of Interest}

The author has no conflicts to disclose.

\section{REFERENCES}

1. Sarin SK, Kumar M, Eslam M, George J, Al Mahtab M, Akbar SMF, et al. Liver diseases in the Asia-Pacific region: a Lancet Gastroenterology \& Hepatology commission. Lancet Gastroenterol Hepatol 


\section{CLINICAL and MOLECULAR}

2020;5:167-228.

2. Yoon JH, Cho SH, Kim DY, Yu SJ, Han KH. Epidemiological and clinical history of viral hepatitis in Korea. Infect Chemother 2021;53:159165.

3. Yim SY, Kim JH. The epidemiology of hepatitis B virus infection in Korea. Korean J Intern Med 2019;34:945-953.

4. Jeong S, Cho Y, Park SM, Kim W. Differential effectiveness of tenofovir and entecavir for prophylaxis of hepatocellular carcinoma in chronic hepatitis B patients depending on coexisting cirrhosis and prior exposure to antiviral therapy: a systematic review and meta- analysis. J Clin Gastroenterol 2021;55:e77-e86.

5. Baik D, Kim BW, Oh JK, Kim KA, Ki M. Costs of viral hepatitis B in the Republic of Korea, 2002-2015. J Viral Hepat 2020;27:156-167.

6. Jourdain G, Ngo-Giang-Huong N, Harrison L, Decker L, Khamduang W, Tierney $C$, et al. Tenofovir versus placebo to prevent perinatal transmission of hepatitis B. N Engl J Med 2018;378:911-923.

7. Cho ER, Shin A, Choi KS, Lee HY, Kim J. Factors associated with use of ultrasonography screening for hepatocellular carcinoma among hepatitis B or C carriers. Cancer Epidemiol 2010;34:713-716. 